\title{
Balint Groups as a Means to Increase Job Satisfaction and Prevent Burnout Among General Practitioners
}

\author{
Dorte Kjeldmand, GP, $P b D^{1,2}$ \\ Inger Holmström, RN, $\mathrm{PbD}^{1}$ \\ ${ }^{1}$ Department of Public Health and \\ Caring Sciences, Section for Health \\ Services Research, University of Uppsala, \\ Uppsala, Sweden \\ ${ }^{2}$ Eksjö Primary Care Centre, Eksjö, Sweden
}

AC Annals Journal Club selection; see inside back cover or http://www. annfammed.org/AJC/.

Conflicts of interest: none reported

\section{CORRESPONDING AUTHOR}

Dorte Kjeldmand, GP, PhD

Eksjö Primary Care Center

SE-57581 Eksjö, Sweden

dorte.kjeldmand@lj.se

kjeldmand@gmail.com

\begin{abstract}
PURPOSE General practitioners (GPS) occupy a central position in health care and often have demanding working situations. This corps shows signs of exhaustion, and many consider quitting their job or plan to retire early. It is therefore urgent to find ways of improving GP's satisfaction with their work. One approach might be Balint group participation. The aim of this study was to explore GPs' experience of participating in Balint groups and its influence on their work life.
\end{abstract}

METHODS We conducted a descriptive, qualitative study. Nine GPs who had participated in Balint groups for 3 to 15 years were interviewed. A phenomenologic analysis was carried out to describe the phenomenon of Balint group participation.

RESULTS The GPs perceived that their Balint group participation influenced their work life. Analyses revealed several interrelating themes: competence, professional identity, and a sense of security, which increased through parallel processes, creating a base of endurance and satisfaction, thus enabling the GPs to rediscover the joy of being a physician.

CONCLUSIONS The GPs in this study described their Balint group participation as beneficial and essential to their work life as physicians in several ways. It seemed to increase their competence in patient encounters and enabled them to endure in their job and find joy and challenge in their relationships with patients. Balint groups might thus help GPs handle a demanding work life and prevent burnout. These groups might not suit all GPs, however, and additional ways to reduce stress and increase job satisfaction should be offered.

Ann Fam Med 2008;6:138-145. DOI: 10.1370/afm.813.

\section{INTRODUCTION}

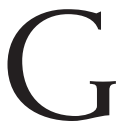
eneral practitioners (GPs) derive greater satisfaction from encounters with patients that develop and maintain relationships and prioritize the distress of patients as compared with encounters that focus on technical aspects of care. ${ }^{1}$ Yet the work of the GP includes emotionally difficult situations, the witnessing of suffering, anxiety, and death, as well as contacts with despairing or demanding patients who cannot be satisfied. ${ }^{2,3}$ As stated by Arnetz, "The doctor-patient relationship is the core of the profession; while it is often gratifying, it is also a source of severe emotional risk."4

Consequently, there are serious signs of exhaustion among GPs in western societies. ${ }^{5-8}$ Such is the case also in Sweden. Recruiting new physicians to general practice is difficult, and many GPs want to quit or retire early. ${ }^{8-12}$ Burnout is a major problem among physicians in general, and preventive strategies are needed.,13

A helpful strategy for overcoming and unburdening oneself of difficult experiences may be to share them with others. ${ }^{71,15}$ For the GP, however, this 
is not easily accomplished. Patients are scheduled regularly, which may result in seeing a patient with a common cold directly after seeing a patient with a terminal illness. Physicians are limited in their ability to share their experiences because of confidentiality, and there is little tradition of debriefing or supervising activities in general practice. Physicians are left with 2 possibilities: either unburdening themselves at home or suppressing the emotions with eventual bad consequences for mental health in the long run. ${ }^{15}$ Moreover, many GPs are confused about their role and obligations in an increasingly secularized and diversified world where people seek explanations and solutions to their miseries in the health care system. ${ }^{9,16}$ These circumstances may lead to mental overload, conflicts of values, and a feeling of loss of control, which are important factors leading to burnout. ${ }^{17-19}$

Continual professional development and reflection in peer groups might be an approach for avoiding burnout. Balint groups may provide such opportunities for GPs and supply them with strategies for handling their work life. Balint groups are active worldwide, but most countries have few of them. ${ }^{20}$ In Sweden, approximately 40 groups were active in 2003, onehalf of which had specialists in general medicine. In the United States, Balint groups are widely used as an educational activity during residency in family medicine ${ }_{1}^{21,22}$ whereas in Europe, many Balint groups consist of GP-specialists with a wide range of experience.

In Balint groups, physicians are trained to implement basic psychodynamic principles with special attention to the physician-patient relationship. ${ }^{23}$ The aim is to improve physicians' skills in handling their patients while simultaneously controlling their personal involvement and awareness of their own feelings during patient encounters. The groups comprise 4 to 10 physicians and 1 or 2 leaders, and meet regularly for several years. At the group meetings, members spontaneously describe patient encounters and the group discusses these encounters, focusing on the story and the feelings it arouses, to facilitate new ways of understanding the physician-patient relationship. ${ }^{24}$ The founder, Michael Balint, talked of creating "a limited though considerable change of his [the physician's] professional personality."23

Research on Balint groups is limited and mainly restricted to short-term interventions in faculty settings. ${ }^{25-29}$ Balint and coworkers allowed the group leaders (all psychoanalysts) to grade each member's capability of comprehensive reflection on his or her relationships with patients. One-half of members were assessed to have made progress in the groups. ${ }^{30}$

In a previous questionnaire study, we compared GPs participating in Balint groups with GPs not having access to Balint groups. ${ }^{31}$ The Balint group participants scored significantly better on issues concerning perceived work environment and control, competence in handling patients with psychosomatic issues, and satisfaction in work. To date, that is the only published study considering the effects of Balint group participation on the work environment. The aim of this study was therefore to explore more deeply GPs' experiences of Balint group participation and its influence on their work life.

\section{METHODS}

We chose a descriptive, qualitative design because of the nature of the study, focusing on the lived experience of the informants. ${ }^{32}$

\section{Sample and Setting}

In Sweden, most GPs work in primary health care centers and are employed by county councils. We conducted a strategic sampling ${ }^{32}$ of informants by contacting the known Balint groups in southern Sweden to obtain names of participating GPs with more than 2 years of Balint group experience. Efforts were made to get a varied sample in terms of sex, age, professional experience, and geographic setting. We contacted 10 potential informants via e-mail and told them about the study. All agreed to participate in an interview, but 1 withdrew later because of lack of time. All informants signed an informed consent contract before the interview. The study was approved by the Ethics Committee of the Faculty of Medicine at Uppsala University.

\section{Interviews}

The interviews were carried out during 2002-2003 by 1 author (D.K.) at each informant's workplace. The interviewer had not previously met any of the informants, but they knew that she was a colleague with Balint group experience. The interviewer used an interview guide with open-ended questions that asked informants about their reasons for joining a Balint group their experiences in the group, both good and bad; whether the group had influenced their work life and encounters with patients; and how they would describe their group experience to a colleague without this experience. To obtain rich and personal descriptions, the interviewer explored and clarified the informants' experiences with probing questions, such as, "Could you give a concrete example?" and "What do you mean by that?" The interviews were conducted in Swedish, lasted 45 to 75 minutes, and were audio recorded and transcribed verbatim by the interviewer.

\section{Analysis}

Modern phenomenology originated from the philosophy of Edmund Husserl and has since developed into 
empirical research methods. ${ }^{33-35}$ Because we sought the meaning of the informants' experience of Balint group participation, we used the empirical phenomenologic psychological method ${ }^{35}$ for our analysis.

This method is similar to Giorgi's descriptive phenomenologic method ${ }^{34}$ in its stepwise procedure but allows more interpretation. The researcher condenses the interview texts, traces out the meaning of the texts, and judges the relevance to the description of the phenomenon in question, while actively holding back his or her own preconceptions. The steps of the analysis are displayed in Table 1 .

The analysis was carried out primarily by 1 author (D.K.) in close cooperation with the other author (I.H.), who actively took part in each step in the process. Differences were resolved by open discussions. The interviewer's preconceptions were addressed in the interviewing phase by actively asking informants for negative experiences, and in the analysis phase by bringing prejudices out for open discussions between authors and in seminars, thus allowing critical scrutiny of the process. ${ }^{32}$

\section{RESULTS}

\section{Informants}

The 9 informants participated in 6 different Balint groups led by 6 different leaders. They were 4 women and 5 men, aged 42 to 60 years. Eight informants were Swedish; 1 was a first-generation immigrant. They had at least 3 years of experience as specialized GPs and were permanently employed at health care centers in different geographic settings. The duration of their Balint group experience ranged from 3 to 15 years (mean, 8 years).

\section{Themes and Subthemes}

Our analysis of these GPs' experiences of how their Balint group participation influenced their work life revealed the following interrelating themes: competence, professional identity, and a sense of security, which increased through parallel processes, creating a base of endurance and satisfaction, thus enabling them to rediscover the joy of being a physician. The themes and subthemes that emerged from the interviews are displayed in Table 2 We further describe them and give examples through quotes below. The quotes were translated from Swedish to English by a professional interpreter.

\section{Competence}

The informants reported that Balint group participation increased their competence in controlling encounters

Table 1. Steps in the Analysis of the Interviews

\begin{tabular}{ll}
\hline Step & Description \\
\hline 1 & $\begin{array}{c}\text { All the interviews were read through repeatedly to get a } \\
\text { good grasp of the whole } \\
2\end{array}$ \\
3 & $\begin{array}{c}\text { The text was divided into meaning units. A meaning unit } \\
\text { starts when the content of meaning shifts } \\
\text { Each meaning unit was examined closely and condensed } \\
\text { into what was relevant to the research question, and the } \\
\text { informant's language was changed into the researcher's } \\
\text { language } \\
\text { The transformed meaning units were reformulated into } \\
\text { themes and subthemes } \\
\text { The themes and subthemes were related to each other in } \\
\text { a general structure of the studied phenomenon }\end{array}$ \\
&
\end{tabular}

\section{Table 2. Themes and Subthemes Resulting From the Analysis} of the Interviews

\begin{tabular}{|c|c|}
\hline Themes & Subthemes \\
\hline $\begin{array}{l}\text { Competence in the physician- } \\
\text { patient encounter gained in } \\
\text { the Balint group }\end{array}$ & $\begin{array}{l}\text { Naming, tracing, and handling difficult emotions } \\
\text { Knowing oneself } \\
\text { Preparing oneself for difficult encounters } \\
\text { Understanding mechanisms of bad encounters } \\
\text { Viewing the patient as a whole person in a biopsychosocial } \\
\text { coherence } \\
\text { Understanding why patients seek health care } \\
\text { Being proactive in consultations }\end{array}$ \\
\hline $\begin{array}{l}\text { Professional identity as recog- } \\
\text { nized in the group }\end{array}$ & $\begin{array}{l}\text { Recognizing difficult encounters as a special and challenging } \\
\text { task as a general practitioner } \\
\text { Learning the limits of one's abilities and obligations } \\
\text { Understanding patient-centeredness as a prerequisite of being } \\
\text { a general practitioner } \\
\text { Having a shared working condition, showing tolerance toward } \\
\text { colleagues } \\
\text { Mirroring oneself in others' stories leading to increased } \\
\text { understanding of the tasks of a general practitioner }\end{array}$ \\
\hline $\begin{array}{l}\text { Sense of security developed } \\
\text { in the group }\end{array}$ & $\begin{array}{l}\text { Long relationship with the other group members } \\
\text { Weaknesses and mishaps are tolerated } \\
\text { Permissiveness, openness, and sincerity in the group } \\
\text { Confidentiality, frames, and firm structure } \\
\text { Feeling of not being alone even between group meetings } \\
\text { Long experience leads to feeling of security }\end{array}$ \\
\hline $\begin{array}{l}\text { Parallel process: general prac- } \\
\text { titioner-patient and Balint } \\
\text { group-general practitioner }\end{array}$ & $\begin{array}{l}\text { Long relationship with both patients and group } \\
\text { Learning to listen patiently to narratives of discomfort } \\
\text { Acknowledging changes over time in both group and patients } \\
\text { Changing one's behavior permanently takes time }\end{array}$ \\
\hline Endurance and satisfaction & $\begin{array}{l}\text { Having good times together, breathing space } \\
\text { Balint group enhances satisfaction with work } \\
\text { Balint group counteracts burnout } \\
\text { Together recognizing the good sides of work }\end{array}$ \\
\hline
\end{tabular}


and handling emotions-both patients' and their own. They reported being able to recognize and name emotions, such as anger, which enabled them to talk about the emotional elements in encounters. They could more easily trace the sources of emotions, whether they originated from their own activated conflicts or were projected from their patients, as exemplified by the following narrative:

I had such problems with a man in his 40 s, whom I experienced as extremely help-seeking ${ }_{i}$ I felt as if he crept up onto my lap, and it was really difficult. I spoke about it in the Balint group, and I understood that it was his regression in his situation that I felt. When we met the next time, I was more prepared and it did not happen again.... I know that I went to that encounter without fear, and that was great.

The informants perceived that they had gotten to know themselves better and could more often understand what happened when patient encounters went wrong. They had also learned ways of keeping structural control over the encounters and being prepared for difficulties, and when the encounter dragged, often put their finger on the heart of the matter:

You come back to what it is about-the pain is not the primary cause, you see what it really is about and you can resist the flow of words from the patient describing the symptoms and break in and focus on what it is really all about ... powerlessness and discomfort ... yes, be more prepared and guide the conversation onto another level.

Another aspect of competence the GPs emphasized was that their approach became more patient centered. Balint group participation was regarded as important for their increased understanding of the patients' psychosocial situation and the important role it played in patients' actions in relation to health care, as voiced by one informant:

We have discussed, we call it "the view of wholeness," but what is wholeness? Sometimes it is not just the patient, but also the spouse who comes in and talks the most. And in fact, wholeness is also both patient and doctor, both make a wholeness that we must acknowledge, and Balint has assisted, of course, to see wholeness and the immense importance the context or the wholeness has to how a person feels.

\section{Professional Identity}

Informants recognized that viewing the patient as a person and not merely as an illness was a central part of their professional identity as GPs. They described how encounters with "difficult" patients had developed into rewarding relationships and how they were really curious about how the next meeting would turn out. The heavy burden of difficult encounters had become a challenge, as is evident in the following comment:
Before I joined the first Balint group, I always thought that the patient who I was about to see, that it would be hard and tiresome. But afterward, this feeling that you have when you are about to enter to see the patient, open the door and so on ... it had disappeared, it felt more like, when best it felt like this is going to be exciting, it will be difficult, but I think I can manage.

The informants reflected on the roles of the GP and seemed to have found useful guidelines. They had understood that there were limits to what they as GPs could accomplish and also to the role they should play in their patients' lives. They perceived that they had been helped by the Balint group to understand that not everything that went wrong was their fault - that patients had responsibility too, and that this shared responsibility was important both for the patients and for their own survival as GPs, as exemplified by the following statement:

But this "being nice," that is, after all, only that you have difficulties putting limits - and that is devastating in the long run, both for oneself and for the patient. You end up digging your own grave. I think the straight way to burnout, that is "just being nice." You are not nice when you do somebody a disservice. So the strength as a doctor ... definitely the best strength you can have as a doctor is the ability to say no. Understand me right, for the benefit of the patient, of course. Accepting anything and doing everything that the patient demands, then you are not a doctor, you do not devote yourself to the art of medicine, you become some kind of checkout assistant and it will lead to an immense dissatisfaction in your work

The informants also perceived that participation in Balint groups had increased their understanding and empathy for colleagues-not only their fellows in the groups but in general. They found it easier to talk about difficulties and even to ask for help in everyday life, especially when their Balint group included colleagues from their workplace.

It has definitely become easier I think, too, to understand, not only the colleagues in the group, but that you understand that colleagues can often have tough times in their work, are tired, and you don't judge so easily. You regard your colleagues, I think, with greater justice. Otherwise maybe you just think that you yourself are overloaded and work away, are fed up, and maybe you are, but you have an understanding of the other person too.

\section{Sense of Security}

Informants described the Balint group as a place of freedom, as a part of one's work life but still free from the ordinary run-of-the-mill responsibilities. The work in the group was very intense and sometimes revolutionary, but also full of tolerance and without performance anxiety. Participants felt safe there, safe to 
uncover insecurity and mishaps, as exemplified by one informant's comments:

Some years ago I was accused of malpractice, and I was strengthened by the group. To be able to talk about it was very important. I was freed then, but I benefit from this all the time, as one always feels threatened by new accusations. We live with this difficult first judgment of cases and suddenly you do something wrong. It makes it easier to live with that thought when I know that we support each other.

The safety developed over a long time and was guarded by the firm frames of the group's structure and confidentiality. The company of peers gave the participants support, and this feeling of strength and security remained with them between the meetings, as told in the interviews. The informants emphasized that their membership in a Balint group was very important and far more valuable than short, intensive courses in consultation techniques. For example, one informant said, "It is enough just to think of the group, then you sort of gain strength in a situation when you feel it's heading in the wrong direction in the contact with a patient."

\section{Parallel Processes}

The relationships between the GP and the Balint group on the one hand and between the patient and the GP on the other were established over a long time and were interpreted to be parallel to each other. The process in the Balint group often mirrored that in the physician-patient relationship, and identifying this association had great educational impact for the informants. ${ }^{36}$ In the group, physicians could put themselves in the patient's shoes, with the attendant feelings of weakness and insecurity, and maybe thereby come to understand the patient's perspective. For example, one informant shared the following:

I don't think that Balint has turned me into a nicer doctor, ... but I think that I can reverse the perspective better, the patient perspective, and maybe better understand why certain feelings arise between some patients and oneself.

Informants described how they were able to transfer elements of the work methods from the Balint group (eg, maintaining a firm structure, focusing and accepting strong emotions, patiently listening to narratives of insecurity, shame, and discomfort) to the physician-patient relationship. As an informant put it, "We have got used to listening for quite a while."

The possibility of having to follow a patient narrative in a series of meetings enhanced informants' learning of patience in building relationships and tolerating insecurity. One informant observed, " ... but it is like that with patient contacts as well. As a genuine GP, you are well aware that it takes time; it's like that in the Balint group as well."

\section{Endurance and Satisfaction}

The Balint group was described as a recurrent place for positive time together with colleagues, a breathing space in an otherwise rather lonesome work situation. In the words of one informant:

[The Balint group is] another type of contact, which is needed because of so much work alone. So it is nice to meet colleagues, when you know that during these hours we will discuss important issues.

Informants described how very sad and troublesome experiences were often difficult to handle without sharing them with others. They were able to use the Balint groups to unburden themselves of these heavy experiences.

I had some very heavy incidents, with young patients dying, younger than me, boys, or young men, whom I knew; and the policemen were very rude. Those situations gave me really bad feelings that I got help and support with in the Balint group ... in a very good way. It was so powerful, that I could have ended as a doctor the next week, such strong emotions; I was completely misused in my profession. But I could get back my joy in work. ... this was very important; it is the most important event I have brought to the Balint group.

The informants regarded the Balint group as a means of avoiding burnout but also noted that it demanded a long-term commitment, as exemplified by the following comments:

[Without the Balint group] ... I might have been charged with malpractice-for prescribing too much medicine, maybe. Or I would have had too many patients and been burned out. I would not have been able to handle the burden. I would have been more sensitive to critics or when patients get angry for some reason.

There are those who think that Balint, that's something you do for a couple of years, and then you have learned it, but that's not the way it is. We work with people, and all the time new difficulties turn up, new emotions, that is, unless you become a zombie.

Even though serious matters were discussed in Balint groups, the groups were not described as a solemn place. On the contrary, the informants related a creative and vitalizing atmosphere with fun and laughter, and with the permission to search for and find the joy of the work as a GP.

I think it's easier to endure, yes, the everyday work, and even see the charm in the work. You should not forget that, it sounds as if it is a way to manage the hardships, but we see the new ... develop as a human being as well, develop the good sides. The job as a GP is such terrific fun, actually. I can't think of another job like it. Maybe there are others, life is so big, but there are such exciting things you experience in the meeting with patients. 


\section{DISCUSSION}

\section{Key Findings}

Mental overload, conflicts of values, and perceived loss of control are important factors leading to burnout. ${ }^{17-19}$ Participating in Balint groups could be one way for GPs to develop strategies to handle difficult situations, rendering them less sensitive to stress. Our findings point to the Balint group as a means for achieving such competence because this method is based on reflection about difficult patient encounters and making use of frustrating experiences and emotions. In this study, we did not directly explore how exactly this competence is achieved, but several mechanisms likely play a role. Some of these mechanisms could be the healing and developing effect of structuralizing painful experiences in narratives, ${ }^{37}$ the increase in understanding of complex events or relationships by reflection in a professional setting, ${ }^{38}$ and the access to peers empathetically engaged in one's distressing situation. ${ }^{39}$ This situation could resemble the patient's situation in the consultation, and thus the GP may understand more about what it is like to be the patient. Group leaders facilitate the process by clarifying questions and suggestions, while carefully protecting the safe milieu and keeping the focus on the physician-patient relationship even when it is difficult-much like the role GPs assume in the patient encounter.

In addition, Balint group participation may lead to an improved physician-patient relationship and may foster a patient-centered approach, as noted by Mead and Bower. ${ }^{40}$ The results from our study support these benefits. The patient-centeredness learned in Balint groups, by enhancing optimum contact between the physician and the patient, may also satisfy the ethical demands that physicians face. Conflicts between ones ethical demands and reality in ones working situation may lead to burnout according to Maslac et al. ${ }^{17}$ By viewing the patients in a patient-centred way, the physicians may experience coherence between their ethical expectations of the job and the reality, in which GPs can only achieve goals acknowledged by the patients and possible in their context. Thus the patient-centred view may lead to enhanced satisfaction in work and less risk of burnout.

The confusion of roles and responsibilities of the GP did not seem to bother these physicians. They had found ways of setting boundaries while at the same time enhancing their patient-centered approach. Freeing themselves from self-induced demands of omnipotence and defining what they actually could do well was crucial to the GPs' process of positively defining their professional identity, which for such a long time many of them had defined as doing whatever nobody else could or would do. The Balint group thus may be a place to learn the patient-centered way ${ }^{40}$ of being a GP while maintaining a healthy work life. ${ }^{7}$
In our view, physicians need guidance, feedback, and support just as much as factual knowledge. In this respect, Balint groups provide an important safe and confidential area for unburdening and containing activity, and GPs should be allowed to participate if they want to. This method demands a long-term commitment, and it should probably be considered more as maintenance than as merely another kind of continual professional development activity. After all, physicians are expensive, more expensive than advanced technical equipment, the maintenance of which no one would question. It should be noted, however, that Balint groups might not be a suitable method for all GPs, and other ways of promoting stress reduction and increasing job satisfaction should be offered in addition.

\section{Methodologic Considerations}

We wanted to explore the lived experience of being a GP participating in a Balint group, which made the qualitative approach appropriate. ${ }^{32}$ As in qualitative studies in general, our study sample was small and the transferability of findings may be limited to people and settings with characteristics similar to those studied here. ${ }^{25,30,41}$ We did not explore negative aspects of Balint groups and problems with dropouts in this study, but we will do so in a forthcoming study.

The interviewer was a GP with Balint group experience, which raises some concerns about methodology. The researcher should know the field in order to generate appropriate interview questions, ${ }^{42}$ but the shared understanding between the informants and the researcher may create blind spots that hinder exhaustive communication, such as effective follow-up questions. On the other hand, the topic of this study relates to emotionally charged episodes, disclosures of mishaps, and feelings of inferiority, as told in the Balint groups. Shared understanding may encourage informants to disclose more about their experiences because they feel safe and confident with a colleague. ${ }^{43}$ The second author's complete lack of Balint group experience enhanced neutrality during analyses.

This study did not aim to explain how results are achieved in Balint groups, but it is an important issue to explore further, as is the extent to which patients experience a better relationship with their Balint group-participating GPs. Although difficulties and dropouts in Balint groups are subject to research, ${ }_{1}^{29}$ it is also important to develop methods to predict which physicians will benefit from Balint group participation.

\section{Implications}

Michael Balint introduced Balint groups as a way to improve GPs' competence in handling patients with neurotic problems and in delivering some minor 
psychotherapy in primary health care for the patients' benefit. A spin-off effect of these groups might therefore be a reduction in the pressure on secondary health care and the economy. Our study suggests that Balint groups may have additional positive consequences. The GPs we interviewed emphasized that Balint groups were their means of avoiding burnout. They described how they together in their Balint groups found joy, challenge, and enthusiasm in their relationships with patients. Patients should benefit from having competent GPs with these incentives. On a larger scale, enabling GPs to endure or even thrive in their job is critically important to the health care system as well.

To read or post commentaries in response to this article, see it online at http://www.annfammed.org/cgi/content/full/6/2/138.

Key words: Balint group; physician-patient relationship; work environment; job satisfaction; burnout; patient-centered care

Submitted June 12, 2007; submitted, revised, September 10, 2007; accepted October 8, 2007.

Prior presentations: 2nd International Conference on Communication in Healthcare, Bruges, Belgium (Balint Training Makes GPs Thrive Better in Their Job), 2004; 14th International Balint Congress, Stockholm, Sweden (The Tale of a PhD on Balint Groups, Part 4), 2005; and 4th Nordic Interdisciplinary Conference on Qualitative Methods, Växjö, Sweden (Satisfaction and Sense of Security) and Uppsala University thesis (The Doctor, the Task and the Group-Balint Groups as a Means of Developing New Understanding in the Physician-Patient Relationship), 2006.

Funding support: Grants were received from the Health Research Council in the South-East of Sweden (FORSS), the Academy for Healthcare, Jönköping County Council (FUTURUM), and the Research and Development Unit for the Elderly (ÄNV), Northwest Stockholm County Council.

Acknowledgments: We wish to thank the participating GPs and the leaders of their Balint groups. Also, thanks go to Ann Malmström for mentorship and encouragement, and to Henning Pedersen, Marie Bäckström-Andersson, and other colleagues at Eksjö Primary Care Centre for making research possible while being a GP.

\section{References}

1. Fairhurst K, May C. What general practitioners find satisfying in their work: implications for health care system reform. Ann Fam Med. 2006;4(6):500-505.

2. Bellon JA, Fernandez-Asensio ME. Emotional profile of physicians who interview frequent attenders. Patient Educ Couns. 2002;48(1):33-41.

3. Horowitz CR, Suchman AL, Branch WT Jr, Frankel RM. What do doctors find meaningful about their work? Ann Intern Med. 2003;138(9):772-775.

4. Arnetz BB. Psychosocial challenges facing physicians of today. Soc Sci Med. 2001;52(2):203-213.

5. Edwards N, Kornacki MJ, Silversin J. Unhappy doctors: what are the causes and what can be done? BMJ. 2002;324(7341):835-838.

6. Sexton R. Maintaining the wellbeing of rural GPs. BMJ Career Focus 2003;326(7391):S101.
7. Spickard A Jr, Gabbe SG, Christensen JF. Mid-career burnout in generalist and specialist physicians. JAMA. 2002;288(12):1447-1450.

8. Kmietowicz Z. Quarter of GPs want to quit, BMA survey shows. BMJ. 2001;323(7318):887.

9. Sibbald B, Enzer I, Cooper C, Rout U, Sutherland V. GP job satisfaction in 1987, 1990 and 1998: lessons for the future? Fam Pract. 2000;17(5):364-371.

10. Swedish Medical Association. Framtidsplaner för distriktsläkare [Future plans for general practitioners]. 1998. http://www.svdlf.se. Accessed Oct 3, 2006.

11. Ohlin E. Ingen ökning av specialister i allmänmedicin trots satsning [No increase in number of specialists in general practice in spite of drive]. Lakartidningen. 2005;102(28):2052.

12. Bodenheimer T. Primary care-will it survive? N Engl J Med. 2006;355(9):861-864.

13. Shanafelt TD, Sloan JA, Habermann TM. The well-being of physicians. Am J Med. 2003;114(6):513-519.

14. Epstein RM. Mindful practice. JAMA. 1999;282(9):833-839.

15. Pennebaker JW. Opening Up: The Healing Power of Expressing Emotions. New York, NY: The Guilford Press; 1997.

16. Berg E. Det Skapende Mellomrommet i Mötet Mellom Pasient og Lege [The Creative Space in the Patient-Physician Encounter] [thesis]. Universitetet i Tromsö, Norge; 2004.

17. Maslach C, Schaufeli WB, Leiter MP. Job burnout. Annu Rev Psychol. 2001;52(1):397-422.

18. Addison RB. Burnout and Balint. In: 14th International Balint Congress. Stockholm, Sweden: 2005:118-124.

19. European Commission. Guidance on Work-Related Stress-Spice of Life or Kiss of Death? Luxembourg, Belgium: Office for Official Publications of the Europeans Communities; 2000.

20. Salinsky J. The Balint movement worldwide: present state and future outlook: a brief history of Balint around the world. Am J Psychoanal. 2002;62(4):327-335.

21. Johnson AH. The Balint movement in America. Fam Med. 2001;33(3):174-177.

22. Johnson AH, Brock CD, Hamadeh G, Stock R. The current status of Balint groups in US family practice residencies: a 10-year follow-up study, 1990-2000. Fam Med. 2001;33(9):672-677.

23. Balint M. The Doctor, His Patient \& The Illness. 2nd ed. London, Eng land: Pitman Medical Publishing Co Ltd; 1964.

24. Johnson AH, Nease DE, Milberg LC, Addison RB. Essential characteristics of effective Balint group leadership. Fam Med. 2004;36(4):253-259.

25. Turner AL, Malm RL. A preliminary investigation of Balint and nonBalint behavioural medicine training. Fam Med. 2004;36(2):114-117

26. Adams KE, O'Reilly M, Romm J, James K. Effect of Balint training on resident professionalism. Am J Obstet Gynecol. 2006;195(5):1431-1437.

27. Margalit AP, Glick SM, Benbassat J, Cohen A, Kats M. Promoting a biopsychosocial orientation in family practice: effect of two teaching programs on the knowledge and attitudes of practising primary care physicians. Med Teach. 2005;27(7):613-618.

28. Sekeres MA, Chernoff M, Lynch TJ Jr, Kasendorf El, Lasser DH, Greenberg DB. The impact of a physician awareness group and the first year of training on hematology-oncology fellows. J Clin Oncol. 2003;21(19):3676-3682.

29. Kjeldmand D. The Doctor, the Task and the Group-Balint Groups as a Means of Developing New Understanding in the Physician-Patient Relationship. Uppsala, Sweden: Uppsala University; 2006.

30. Balint M, Balint E, Gosling R, Hildebrand P. A Study of Doctors. London, England: Tavistocks Publications Limited; 1966.

31. Kjeldmand D, Holmström I, Rosenqvist U. Balint training makes GP thrive better in their job. Patient Educ Couns. 2004;55(2):230-235. 
32. Malterud K. Qualitative research: standards, challenges, and guidelines. Lancet. 2001;358(9280):483-488.

33. Husserl E. The Idea of Phenomenology. Dordrecht, The Netherlands: Kluwer Academic Publishers; 1999.

34. Giorgi A. Sketch of a psychological phenomenological method. In: Giorgi A, ed. Phenomenology and Psychological Research. Pittsburgh PA: Duquesne University Press; 1985:8-22.

35. Karlsson G. Psychological Qualitative Research from a Phenomenological Perspective. Stockholm, Sweden: Almqvist \& Wiksell International; 1995.

36. Playle JF, Mullarkey K. Parallel process in clinical supervision: enhancing learning and providing support. Nurse Educ Today. 1998;18(7):558-566.

37. Kleinman A. The Illness Narratives: Suffering, Healing $\&$ the Human Condition. New York, NY: Basic Books; 1988.
38. Sandberg J. Understanding the basics for competence development. In: Velde CE, ed. International Perspectives on Competence in the Workplace. Dordrecht, The Netherlands: Kluwer Academic Publishers; 2001:9-25.

39. Salinsky J, Sackin P. What Are You Feeling, Doctor? Abingdon, United Kingdom: Radcliffe Medical Press; 2000.

40. Mead N, Bower P. Patient-centredness: a conceptual framework and review of the empirical literature. Soc Sci Med. 2000;51(7):1087-1110.

41. Hamberg K, Johansson E, Lindgren G, Westman G. Scientific rigour in qualitative research-examples from a study of women's health in family practice. Fam Pract. 1994;11(2):176-181.

42. Larsson J. Anaesthetists and Professional Excellence [thesis]. Uppsala, Sweden: Uppsala University; 2004.

43. Chew-Graham CA, May CR, Perry MS. Qualitative research and the problem of judgement: lessons from interviewing fellow professionals. Fam Pract. 2002;19(3):285-289. 